\title{
Civil war, Social Capital and Resilience in Uganda
}

\author{
Giacomo De Luca* and Marijke Verpoorten ${ }^{\dagger}$
}

\begin{abstract}
We show that armed conflict in Uganda affects social capital as measured by trust and associational membership. Relying on three rounds of nationally representative individuallevel data bracketing a large number of violent events, we find that self-reported generalized trust and associational membership decreased during the conflict in districts in which violent events took place. But we also find evidence for a rapid recovery of social capital in the aftermath of violence. Results from a variety of identification strategies, including differencein-difference and instrumental variable estimates, suggests that these relationships are causal.
\end{abstract}

Keywords: social capital; trust; civil war; Uganda.

\section{Introduction}

This paper aims to increase the understanding of the legacy of civil war on social capital. What is the impact of civil war on social networks? How does violence affect trust? And more importantly, are these impacts persistent, or even permanent? Providing an answer to these questions is important because of the significant role played by social capital in economic development (Beugelsdijk et al. 2004, Guiso et al. 2004, Knack and Keefer 1995, 1997, Sobel 2002, Weil 2009, Woolcock and

\footnotetext{
*University of York, YO10 5DD, United Kingdom, phone: +44 1904324674 and LICOS - Centre for Institutions and Economic Performance (University of Leuven). e-mail: giacomo.deluca@york.ac.uk

${ }^{\dagger}$ IOB - Institute of Development Policy and Management (University of Antwerp), Lange Sint Annastraat 7, 2000 Antwerpen, phone: +32 32655774, LICOS - Centre for Institutions and Economic Performance (University of Leuven). e-mail: marijke.verpoorten@uantwerp.be
} 
Narayan 2000, Zak and Knack 2001).

We adopt a difference-in-differences estimation method relying on three rounds of nationally representative individual-level data bracketing a large number of violent events that occurred in Uganda in the period between 2000 and 2012. Our findings indicate that both self-reported trust and associational membership tend to decrease during the conflict in the affected districts. At the same time, we find evidence of a strong recovery process a few years after the violence has ended. The difference-in-differences estimation method, along with the inclusion of district- and individuallevel controls, provides a solid basis for our empirical analysis. Nevertheless, the potential issue of endogeneity of conflict intensity remains in establishing a causal effect of violence on social capital. Violence may be the consequence rather than the cause of decreasing levels of trust and participation in associations, because, for instance, rebel recruitment may be easier in regions where mistrust is on a rise. We therefore turn to an instrumental variable strategy to address the potential endogeneity in conflict distribution, adopting a distance measure to instrument for conflict intensity. ${ }^{1}$ The IV estimations broadly confirm the OLS findings.

We also explore the mechanisms through which violence may have affected the dynamics of social capital highlighted above. Our analysis suggests that during the conflict Ugandans increased caution towards certain categories of individuals associated with the perpetrators of violence. This targeted watchfulness, however, faded away only a few years after the violence.

How do these findings fit in the existing literature on the impact of violence on social capital? Early contributions to this debate argued that civil wars, which are fought between opposing factions in a society, disrupt the society's social fabric thus endangering its political stability and economic recovery (Colletta and Cullen 2000, Collier et al. 2003).

This rather pessimistic view has been challenged by recent micro-level studies. Studying the aftermath of the 1991-2002 civil war in Sierra Leone, Bellows and Miguel (2006, 2009) have shown

\footnotetext{
${ }^{1}$ The use of distance measures as instruments is a common approach in the empirical literature on civil war. See, for example, Akresh and De Walque (2008), Miguel and Roland (2011), Serneels and Verpoorten (forthcoming), Voors et al. (2012).
} 
that victimization during the conflict increased collective action, in the form of political participation. Similar positive findings have been presented in several recent studies both using survey data and behavioral experiments run in post-civil war countries (Adhvaryu and Fenske 2013, Blattman 2009, De Luca and Verpoorten forthcoming, Gilligan et al. 2014, Voors et al. 2012).

On the other hand, another set of recent contributions adds to the more pessimistic viewpoint. First, Cassar et al. (2011) show how conflict exposure in post-war Tajikistan undermines trust and fairness within local communities, decreases the willingness to engage in impersonal exchange, and reinforces kinship-based norms of morality. Second, Rohner et al. (2013), studying the aftermath of the conflict in northern Uganda, report lower levels of trust and reinforced ethnic identity in the affected districts. Similarly, Becchetti et al. (2014) document that the level of trustworthiness reduces significantly among individuals victimized in the 2007 Kenyan violence, when playing common pool resource games with individuals from other ethnic groups. Finally, Bozzoli et al. (2010), studying the impact of conflict on expectations relying on a 2007 survey conducted in northern Uganda, find that timing matters: whereas pessimistic expectations prevailed shortly after the experience of conflict, optimistic expectations were positively related to conflict intensity in the distant past.

Our findings mediate between the optimistic and pessimistic viewpoints: we find a negative impact of conflict on social capital and trust, but a fast recovery once the violence has stopped. This suggests that the mixed evidence in the existing literature may depend on the different timing of the analyses in the various studies, some addressing the impact of civil war right after the end of the violence, some later on. Reverse causality is also an issue which potentially invalidates studies which cannot rely on a baseline survey pre-dating the violence. More research is needed on the persistence of the impact, the possible heterogeneity of the impact related to the nature and timing of civil war, and on the underlying mechanisms.

This leads to the contributions of the present article. First, among the studies looking at 
the impact of civil war on social capital this is the first study that relies on three rounds of data, one of which took place before the bulk of the violence occurred, one towards the end of violence, and one several years after the end of violence. This setup allows us to investigate the dynamics of social capital along the different phases of the civil war experience and assess the persistence of the impact of violence on social capital. The different survey rounds, bracketing a peak in violence of more than 618 violent events in a year in the affected area, also allows us to adopt a difference-in-difference estimation, studying the change in trust and associational membership upon a continuous treatment equal to the number of district-level battle days. Second, we explicitly study the impact of violence on associational membership, generally neglected in the conflict literature. Since a person is less likely to cheat someone who is a member of his social network, social capital makes people more trustworthy (Coleman 1988). As a consequence, the disruption of associational membership may slow the recovery of social capital in the aftermath of the violence. Third, based on our results and additional analysis, we investigate the mechanisms through which civil war may affect social capital.

Rohner et al. (2013) use the same data sources as we do. They investigate the effects of the Ugandan conflict on ethnic cleavages, trust, and the economic situation in the post-war period, focusing on the impact in 2008, only a year after the end of the violence. Their results report lower levels of trust and reinforced ethnic identity in the districts affected by the violence. There are several dimensions along which we differentiate from their study. First, we extend the analysis to assess the impact during, and 5 years after the violence. Second, we adopt a difference-in-difference estimation method which allows us to control for district level time invariant unobservables. ${ }^{2}$ Third, we add associational membership to the outcome variables. Fourth, we investigate the potential mechanisms through which violence may impact social capital. The differences in the two papers make their contributions complementary: while Rohner et al. (2013) stress the negative short-run

\footnotetext{
${ }^{2}$ Given this difference-in-difference approach we restricted the analysis to social capital variables for which survey questions were asked identically across the three surveys.
} 
post-war impact, we provide an important qualification of their results concerning the timing, and duration of the impact, as well as the mechanisms underpinning the dynamics of social capital in violent environment.

In the next section, we present the data and provide relevant background information on the armed conflict in Uganda. In section 3, we detail our empirical strategy, of which the results are presented in section 4 . Section 5 presents a discussion of the possible underlying mechanisms. The last section concludes.

\section{Data and Background}

\subsection{Social capital}

The data on social capital is taken from the Afrobarometer (AB), an independent, non-partisan research project that measures the social, political, and economic atmosphere in Africa. ${ }^{3}$ We use three rounds of AB survey data collected in Uganda in 2000, 2005 and 2012. We do not use the 2002 and 2008 AB surveys (except for one robustness check). The 2002 survey does not cover the districts most affected by the civil war, while the questions on social capital included in the 2008 survey are not comparable to those in the 2000 and 2005 surveys and therefore cannot readily be analyzed in a difference-in-difference model.

Each survey includes information on approximately 2,400 individuals of voting age. The samples are nationally representative and geographically stratified across 33 districts in 4 regions, including both urban and rural areas. In Table 1, we give the number of observations per region and per survey year, which show that all four administrative regions of Uganda are well represented in the three survey years.

Table 1 about here

${ }^{3}$ The data and survey instruments are available from www.afrobarometer.org. 
In the seminal work by Putnam (1993), social capital is defined as "the features of social life, networks, norms and trust that enable participants to act together more effectively to pursue shared objectives". Social capital arises when people interact in a number of settings, ranging from membership in an organization to attendance of religious services or just dinner with a group of friends. A commonly used measure of social capital is the level of self-reported generalized trust. Apart from being a highly subjective measure, the generalized trust measure has been shown to capture trustworthiness more than trust itself (Glaeser at el. 2000).

An alternative measure of social capital less prone to these criticisms is the intensity of associational membership. Since it constitutes a factual information, associational membership is less likely to be interpreted differently by different respondents. The frequency of associational membership is expected to capture the level of social capital in the society, e.g. because a person is less likely to betray a member of the same social network (Coleman 1988, Putnam 2000).

The $A B$ surveys include questions on both of these dimensions of social capital: trust and associational membership. We restrict our analysis to those questions that are comparable across survey rounds in terms of question formulation and response categories, which leaves us with five questions - one on trust and four on membership. The question on trust concerns the respondent's level of generalized trust and is formulated as follows: "Generally speaking, would you say that most people can be trusted or that you must be very careful in dealing with people?" The answer categories are "You must be very careful" (coded as 0), and "Most people can be trusted" (coded as 1). The questions on membership are introduced as follows: "Now I am going to read out a list of voluntary organizations. For each one, could you tell me whether you are an official leader, an active member, an inactive member, or not a member of that type of organization?" The list of organizations includes (i) a religious organization like a church or a mosque, (ii) a trade union or farmer's organization, (iii) a professional or business organization, and (iv) a development association. In the 2012 survey the question on membership covers only development associations. 
We code the answer categories as follows: (0) Not a member, (1) Inactive member, (2) Active member, and (3) Official leader. In the empirical analysis, we check the robustness of our results against different ways of coding the answers.

A summary of the social capital variables and their codings is provided in Table 2. Overall, we find rather low levels of trust with less than $20 \%$ of the respondents answering that most people can be trusted. Membership is highest in religious organizations, with more than $80 \%$ of the respondents reporting that they were a member of a religious organization (inactive, active or leading). The other types of organizations only involve the membership of $20 \%$ to $30 \%$ of the population.

Between 2000 and 2005 generalized trust decreased by 2 percentage points on average, and membership of a religious organization increased slightly from $80 \%$ to $83 \%$, but these changes are not significant. Larger and significant changes take place in membership in a trade union/farmer organization (a decrease of 13 percentage points), a professional/business organization (a decrease of 8 percentage points), and a community development organization (an increase of 6 percentage points). It is noteworthy that there are large differences across regions despite the relatively small changes in the averages. For example, self-reported trust increased by 10 percentage points in the western region, while it decreased by 12 percentage points in the northern region.

Similarly, between 2005 and 2012 generalized trust remains relatively stable on average, but it sharply increases in the northern region.

Table 2 about here

\subsection{The Conflict}

The conflict intensity data are taken from the Armed Conflict Locations Events Data (ACLED), which is based on the screening of news reports and provides geo-referenced information on ap- 
proximately 4,506 violent events in Uganda between 1962 and 2012 (Raleigh et al. 2010). ${ }^{4}$

The violent events include battles between armed groups $(2,878)$ and attacks on civilians $(1,628)$. We focus on the activities of the Lord's Resistance Army (LRA), an armed group founded in 1987 by Joseph Kony. LRA events increased from 308 events in the period 1995-1999, to 1,888 events in the period 2000-2005, and declined to just 96 events in the period 2006-2012. The LRA events were thus at a high in the period 2000-2005. This is illustrated in Figure 1.

Figure 1 about here

Figure 1 indicates that, after a period of relative peace following the power seizure by Museveni in 1986, the number of events started to rise in 1995. The Lord's Resistance Army (LRA) was able to intensify its activities in 1995 mainly because of support by the Sudanese government (Dolan 2009). ${ }^{5}$

The bulk of LRA violence fully unraveled in the period 2002-2005 following a military operation in southern Sudan by the Ugandan army - the "Iron Fist" - intended to destroy the LRA supply bases (Dolan 2009). LRA bases were, indeed, destroyed and many rebels killed. The mission was however considered a failure, because the LRA forces managed to outflank the Ugandan army and attack further south in Ugandan districts until then relatively untouched by the conflict, e.g., Apac and Lira (Allen 2006, Dolan 2009). Starting from 2006, however, LRA activities first moved out of Uganda into southern Sudan and into the Democratic Republic of Congo (2006-2008) and then further west reaching the Central African Republic after 2008 (Accord 2010). This released the pressure on civilians and opened the way to peace in northern Uganda.

To cross-check the ACLED data and verify whether the patterns of violence sketched above are

\footnotetext{
${ }^{4}$ The ACLED event data is compiled by screening news articles with language recognition software, which on average yields good results. However, in some cases press accounts may be biased, because very insecure areas may be difficult to access or because computer news screening may be sensitive to the language in which events are reported (Restrepo et al. 2006; Verpoorten 2012).

${ }^{5}$ Kony's movement gathered armed groups reluctant to settle with Kampala's new government and was initially called the Lord's Salvation Army, then the United Democratic Christian Forces, and eventually, from 1994 onward, the Lord's Resistance Army (Allen 2006, Doom and Vlassenroot 1999). The LRA received assistance from Sudan in retaliation for Ugandan support of a rebel group operating in southern Sudan.
} 
in line with individual-level perceptions of violence of the respondents, we examine the following question that was included in the $2005 \mathrm{AB}$ survey: "Please tell me if the following things are worse or better now than they were a few years ago, or are they about the same: Safety from crime and violence?". We code the answer to this question as follows: (1) Much better, (2) Better, (3) Same, (4) Worse, (5) Much worse. Given the trends in the LRA events described above, we expect 2005 respondents in LRA-affected districts to report worsening safety conditions. This is exactly what we find. We find a positive and significant correlation between the LRA treatment (LRA events in 2000-2005) and the respondents' perception of the trend in violence and crime, indicating that, in line with the rising trend in ACLED events in LRA districts, the respondents perceived a decrease in safety.

\subsection{Linking social capital to the conflict}

To construct our dataset, we merged the AB data with the ACLED data at the district level, which is the smallest administrative unit they have in common (the ACLED data is geo-coded but the $\mathrm{AB}$ data is not until 2008 and the $2000 \mathrm{AB}$ baseline includes only district names). Doing so yields a dataset of approximately 7,000 individual level observations across 33 districts. In what follows, we will use the ACLED conflict data as a treatment to study the change in social capital upon conflict. Before doing so, two issues have to be discussed.

First, although LRA violence escalated after our baseline year, a non-negligible number of events took place before 2000 (about 13\% of all LRA events). This pre-2000 LRA activity was largely (for $80 \%$ ) confined to one particular geographic region, "Acholiland"(Kitgum and Gulu districts), while LRA violence outside Acholiland only took off after 2000. Hence, while the estimated LRA treatment should be interpreted as the impact of continued and escalating violence on social capital, a somewhat cleaner treatment effect can be discerned when focusing on LRA activities outside Acholiland. Therefore, as a robustness check we also run a specification of our empirical 
model in which Acholi districts are dropped (in section 5).

Second, that the AB survey was conducted in times of violence as well as amidst a huge refugee crisis following violence raises the issue of sample selection bias. For instance, because of insecurity, the surveys may have excluded the most affected individuals in certain districts. In order to verify this, we consulted the local $\mathrm{AB}$ team that conducted the survey. We learned that, when an enumeration area within a district was highly insecure, the enumeration area was replaced by a more secure area within the same region. The substitution followed the composition of the original sample in terms of language and ethnicity as well as the direction of displacement of the individuals in the original sample, often ending up with a sample of within-district internally displaced people (IDP) (correspondence with Francis Kibirige). This approach was facilitated by the maintenance of local administrative structures in the IDP camps and also by the moving of the IDP within their own district. For instance, Lehrer (2010) studying IDP camps in the Pader and Lira districts of northern Uganda, reports that on average households' ancestral lands were located less than 5 miles from the IDP camp in which they reside. Given this approach and given the fact that more than $90 \%$ of the population was living in these local IDP camps, we can be fairly confident that the $\mathrm{AB}$ survey is representative at the district level for each survey year. ${ }^{6}$ Moreover, since substitution was confined to highly insecure areas, it basically would only cause potential bias for the impact of LRA violence in Acholiland. In section 5 we run several robustness checks to address selection bias, including dropping Acholiland from the sample.

\footnotetext{
${ }^{6}$ For instance, figures released by the Internal Displacement Monitoring Centre reveal that, by 2005, $98 \%$ of the entire population of Gulu district was living in IDP camps located within Gulu (www.internal-displacement.org).
} 


\section{$3 \quad$ Empirical strategy}

\subsection{Estimation models}

To identify the impact of violence on social capital, we use a difference-in-differences estimation that exploits variation in the violent events across districts and over time. The treatment is a continuous variable equal to the logged number of violent events occurring between the implementation of the 2000 and 2005 (or 2000 and 2012) AB surveys. ${ }^{7}$ The treated group are the households located in the districts where violence took place. In other words, the empirical identification strategy relies on the comparison of the change in social capital in 2000-2005 (2000-2012) across areas with low violence intensity and areas with high violence intensity.

Formally, the first empirical model, testing for the impact of violence on social capital during the conflict, can be written as follows:

$$
\begin{aligned}
S_{i, t, d}= & \alpha_{1} \text { year }_{2005}+\alpha_{2}\left(B_{2000-2005, d} * \text { year }_{2005}\right) \\
& +X_{i, t, d}^{\prime} \Psi+\left(D_{d}^{\prime} * \text { year }_{2005}\right) \Theta+\eta_{d}+\varepsilon_{i, t, d}
\end{aligned}
$$

where $i$ indexes individuals, $d$ districts and $t$ survey years. The variable $S_{i, t, d}$ denotes individuallevel social capital. $B_{2000-2005, d}$ denotes logged events per district in the period 2000-2005; and year $_{2005}$ is an indicator variable taking one for respondents in the 2005 survey. Thus, the coefficient of interest is $\alpha_{2}$, which is the coefficient of the interaction term between $B_{2000-2005, d}$ and year 2005 . To reduce heterogeneity across the observations, we control for a number of relevant individuallevel characteristics. The vector $X_{i, t, d}$ denotes a set of individual-level covariates, including the respondent's age, age squared, a gender indicator variable, an indicator variable that equals one if the respondent lives in an urban location, ten fixed effects for the respondent's ethnicity, and the educational level of the respondent (all recorded in the AB). We also control for district fixed

\footnotetext{
${ }^{7}$ For instance, in the case of violent events between 2000 and 2005 we include events that occurred after the last 2000 survey interview (26 June 2000), and before the first 2005 survey interview (12 April 2005).
} 
effects $\left(\eta_{d}\right)$ and for a set of district-level characteristics $\left(D_{d}\right)$ interacted with year ${ }_{2005}$, including violence perpetrated by other groups during the time span considered and ethnic fractionalization. ${ }^{8}$ By doing so, we can rule out that the impact of violence on social capital is confounded by different degrees of ethnic heterogeneity across the affected districts. All explanatory variables are summarized in Table 3. Finally, $\varepsilon_{i, t, d}$ is the standardized error term clustered at the district level across urban and rural strata, since it is likely to be correlated both within district and within urban and rural strata. ${ }^{9}$

Table 3 about here

The second empirical model, investigating the persistence of the impact, can be written as follows:

$$
\begin{aligned}
S_{i, t, d}= & \alpha_{1}^{\prime} \text { year }_{2012}+\alpha_{2}^{\prime}\left(B_{2000-2012, d} * \text { year }_{2012}\right) \\
& +X_{i, t, d}^{\prime} \Psi^{\prime}+\left(D_{d}^{\prime} * \text { year }_{2012}\right) \Theta^{\prime}+\eta_{d}^{\prime}+\varepsilon_{i, t, d}^{\prime}
\end{aligned}
$$

where the only change with respect to equation 1 is that the 2012 survey is used instead of the 2005 one. The coefficient of interest in Eq. 2 is $\alpha_{2}^{\prime}$, which identifies that impact of violence on the level of social capital in $2012^{10}$.

Since the answer categories for the social capital questions in the AB surveys are categorical, we have the option between two different estimation strategies. First, we can maintain the categorical nature of the answers and estimate an ordered probit model. Second, we can estimate our empirical model by OLS, treating the categorical answer as if they were part of a continuous scale. We use the latter approach in the baseline result and report the former as a robustness check. ${ }^{11}$

\footnotetext{
${ }^{8}$ Ethnic fractionalization is calculated from the 1991 Ugandan population census accessed through IPUMS at the Minnesota Population Center (2010).

${ }^{9}$ Cameron and Miller (2015) warns about clustering standard errors with too few clusters and argue that more than 50 clusters are needed when observations are unbalanced across clusters. Since our level of clustering results in 61 clusters, we exceed this threshold.

${ }^{10}$ No LRA violence occurred in the country between 2007 and 2012.

${ }^{11}$ One advantage of using OLS is that it allows us to estimate the standard IV model. This is also the approach taken by Nunn and Wantchekon (2011) in their analysis of the AB trust data.
} 


\subsection{Mechanisms and Hypotheses}

The literature proposes at least three possible mechanisms that link war or trauma to inter-personal relations. First, in war environments, information acquisition may be more difficult and costly. To reduce the costs of acquiring information, individuals may turn to the use of heuristic decision making strategies, or "rules-of-thumb" (Boyd and Richerson 2005). Very concretely, in a highly insecure environment, a general rule of mistrust may yield the highest payoff. We will refer to this mechanism as the rule-of-thumb. Such rules may become entrenched in culture, and thus survive the situation in which they came into existence. For example, Nunn and Wantchekon (2011) refer to this mechanism to explain the persistent impact of historic slave trade on mistrust in SubSaharan Africa. Second, traumatic experiences can result in real psychological change affecting in its turn self-protective behavior and a change in perception of other individuals (Weinstein 1989), whereby positive change is not excluded. For example, Bauer et al. (2014), studying the Sierra Leone conflict, found that greater exposure to war created in young individuals ( 7 to 20 years old) a lasting increase in egalitarian motivations toward their in-groups but not their out-groups. Collins et al. (1990) show that the "recognition of one's vulnerability" may enhance the value of social networks, thereby fostering pro-social behavior. We will refer to this mechanism as the psychological change. Finally, if trust is partly the result of social interactions, then a breakdown of social networks, e.g. community groups, due to displacement or inter- and intra-community violence, may lead to decreased trust levels (de Jong 2002). We will refer to this mechanism as the interaction frequency.

Guided by these three mechanisms, we formulate the following hypotheses with respect to our coefficients of interest.

If individuals adopt a simple rule of thumb to deal with people in a unsafe environment, mistrust would probably emerge $\left(\alpha_{2}<0\right)$. Similarly, if lack of trust results from reduced interaction, then conflict is likely to reduce trust, because an unsafe and violent environment decreases the frequency 
of recreational and professional interaction $\left(\alpha_{2}<0\right)$. If, however, experiencing violence causes a psychological change, the expected effects on social behavior may even be positive $\left(\alpha_{2}>0\right)$, as argued by Collins (1990).

The second hypothesis relates to the persistence of the effect. The psychological change mechanism would predict a long-lasting effect $\left(\alpha_{2}^{\prime}>0\right.$ whenever $\left.\alpha_{2}>0\right)$, whereas the rule-of-thumb and the interaction frequency mechanisms are also compatible with more short-lived effects $\alpha_{2}^{\prime}=0$. Indeed, once the emergency is over, individuals may return to their social behavior, as a general rule of mistrust does no longer yield the highest payoff (although the rule-of-thumb may also survive if it has become entrenched in culture, e.g. after a very long period of insecurity as was the case for slave trade). Similarly, when the violence stops, social interaction may flourish, and revert to the pre-violence levels of social capital.

\section{Empirical results}

\subsection{Baseline results}

Table 4 shows the estimation results of Equation 1 (left panel) and 2 (right panel). The estimated coefficient $\alpha_{2}$ indicates a decrease in generalized trust, and in membership in religious and community/development organizations (Columns 1,2 and 5), but is insignificant in explaining the change in membership in economic associations (trade union/farmer \& professional/business). The magnitude of the impact is substantial: for instance, according to our estimate in column (1) doubling the number of LRA battle events leads to a decrease in generalized trust of 0.028 , which is a sizable effect considering the average generalized trust of 0.15 for the whole sample in 2000 (see Table 3). ${ }^{12}$ Similarly, doubling the number of LRA battle events reduces participation in community/development organizations by 0.079 , relative to the average of 0.56 for the whole

\footnotetext{
${ }^{12}$ Assuming the number of LRA battle events to double represents a meaningful quantification exercise, as the standard deviation of this variable is about three times its mean.
} 
sample in 2000.

Table 4 about here

Moving to the estimation of Equation 2, we can run our model only on generalized trust and membership in development organization as the other information is not included in the 2012 survey. We find that individuals living in districts exposed to LRA violence do not feature any differential trend in generalized trust across the 2000-2012 period as compared to other districts (Column 6), whereas their participation in development organizations increases more than in other districts (Column 7). These findings for the period 2000-2012 indicate considerable recovery. ${ }^{13}$ This is confirmed by results, shown in appendix Table A.1, where we look at the change in social capital between 2005 and 2012, and find that social capital increased more in areas featuring LRA violence.

Overall, the results in Table 4 indicate that social capital decreases in areas affected by violence: generalized trust and associational membership in religious and community development association decline in the districts hit by LRA violence compared to the control districts. We found no negative impact of civil war on the frequency of association in business-related organizations (trade/farmers and professional associations). This finding may relate to the immediate economic costs involved in reducing interaction in this type of organization. ${ }^{14}$ We also document that social capital strongly increases in the post-conflict phase. Generalized trust returns to its pre-violence levels, recovering completely only a few years after the negative shock.

\footnotetext{
${ }^{13}$ Previous studies have argued that social capital and trust may be influenced by the ownership of a TV and/or radio and by the individual employment status (Rohner et al. 2013). In the supplementary material we show that controlling for individual-level exposure to TV and radio news, or employment status does not affects the results in Table 4.

${ }^{14}$ The results of our robustness checks in the next section, where we isolate the impact of fatalities on social capital, seem to support this interpretation. Where the civil war shows its more violent face, thereby increasing the risks of association and possibly reducing the returns of economic activities, the frequency of association in trade and farmer organization is also negatively affected.
} 


\subsection{Robustness checks}

We perform six types of robustness checks. First, we address the potential issue of violence taking place before 2000 and the suitability of our control group. Second, we control for alternative factors - besides the direct impact of violence, that may drive our findings. As alternative factors, we consider migration, concentration in IDP camps and NGO-mobilization. All these results are condensed in Table 5, in which we report only the coefficients for the interaction terms of interest. Third, we check whether our results are robust with respect to the use of alternative estimation models. Fourth, we replicate our estimates with alternative measures of violence. Table 6 summarizes the results of these tests. Next, we reproduce our results adopting the same empirical strategy proposed in Rohner et al. (2013). ${ }^{15}$ Finally, to tackle potential endogeneity issues or attenuation bias (conflict events may be measured with error), we repeat our estimates when instrumenting for violent events.

\subsubsection{Testing alternative explanations}

\section{The 2000 baseline}

In Figure 1 we pointed out that, although violence escalated after our baseline year, a nonnegligible number of LRA events took place before 2000. To account for the timing of the violence, we capture separately the impact of the violence in the non-Acholi districts, where LRA violence took off only after 2000, still controlling for impact of the violence in Acholi districts. The results of this exercise, reported in the first row of Table 5 , are qualitatively similar to our main specification presented in Table 4.

Table 5 about here

\section{The control group}

\footnotetext{
${ }^{15}$ We thank Rohner and coauthors for sharing their data and replication files with us.
} 
Our empirical strategy relies on the comparison of the change in social capital between individuals living in heavily war-affected districts (located mostly in the North of the country) and individuals living in less affected districts (located mostly in the South). Thus, these latter districts are used to proxy the counterfactual: what would have happened if violence would not have taken place? This is a valid approach if both groups of districts are broadly comparable in terms of other potential determinants of the change in social capital. To put this approach to a test, we estimate our empirical model using as a control group only districts in the northern part of the country, and separately controlling for the change in social capital experienced in the southern districts.

This north-south division of the sample follows the division of Uganda along ethnolinguistic lines: the southern part is exclusively Bantu, whereas the northern part is almost exclusively of Nilotic origin (Lewis 2009). ${ }^{16}$ The results, reported in the second panel of Table 5, are very similar to our baseline results.

\section{Migration}

Another potential caveat relates to sample selection, which may drive our results if the population sampled substantially changed across the different survey rounds. In particular, selective outmigration may affect our social capital variables. Our results may for instance capture a decrease in average social capital in violent districts due to outmigration of high social capital individuals by 2005 and a recovery to the 2000 social capital levels due to the return of migrants by 2012 , when safety had been restored. This potential "purging effect", as termed by Gilligan et al. (2014) in their study on Nepalese violence, would be compatible with our results, but has fundamentally different implications, as it would not affect the individual-level social capital, but rather reallocate social capital from violent to safe regions (and back).

Looking at the 2005 LSMS survey implemented in Uganda, and representative at the national level, we learn that $10.9 \%$ of the migrating individuals moved because of insecurity. ${ }^{17}$ Over $70 \%$

\footnotetext{
${ }^{16}$ The districts of Nilotic origin used in this test are: Apac, Arua, Gulu, Kitgum, Lira, Nebbi, Katakwi, Kumi, Soroti.

${ }^{17}$ The 2009 LSMS survey indicates that only $2 \%$ of migrants moved because of insecurity over the previous 5
} 
of these individuals originated from the northern districts of Gulu, Kitgum, Apac and Lira. Consequently, the test reported in the first panel of Table 5, capturing the impact of violence outside Acholiland, constitutes a first piece of evidence that the "purging effect" is not the driving factor behind our findings.

To further assess the potential impact of selective migration, we introduce an artificial selection in our baseline sample of 2000. In particular, we mimic the alleged selective outmigration triggered by war in the baseline sample. If selective outmigration has the potential to affect our results, this artificial selection in the baseline sample should then cancel out our results. We find that excluding $10 \%$ of 2000 respondents from the top of the distribution of social capital does not affect our qualitative results (third panel of Table 5). ${ }^{18}$ In other words, even when assuming a strong positive correlation between social capital and migration, and considerable migration, the test suggests that selection bias is unlikely to strongly affect our results. ${ }^{19}$

A final alternative approach can be helpful in dealing with potential out migration. ${ }^{20}$ We define conflict intensity at the ethnic level, and trace social capital dynamics across ethnic groups over the course of the conflict. If, for instance, Acholi individuals have been most heavily targeted by the violence, and may have migrated to relatively safer districts as a result of violence, running the analysis at the ethnicity level should allow us to reduce the potential bias due to migration. The results of this exercise, reported in panel 4 of Table 5 , suggests a consistently negative impact of violence across all different social capital variables in 2005 and confirms the post-violence full recovery in social capital.

\section{Internal displacement}

A separate issue relates to the nature of the treatment experienced by individuals living in the years, which confirms that the bulk of migration took place before 2005 .

${ }^{18}$ By excluding $15 \%$ of 2000 respondents the coefficient for generalized trust in 2005 turns non significant, and by excluding $20 \%$ of them also the coefficient for associational membership in community and development organizations in 2005 turns non significant. The (negative) sign of both coefficients remains unaffected.

${ }^{19}$ The results for the 2000-2012 analysis are artificially biased upwards by this strategy, as we are reducing the average district social capital in 2000.

${ }^{20}$ We thank an anonymous referee for this suggestion. 
northern districts during LRA operations. As already mentioned, the AB survey was conducted when violence was ongoing as well as amidst a huge refugee crisis. In the districts most heavily affected by the violence the vast majority of the population was living in local IDP camps to better enable protection from LRA attacks. The effects identified in our analysis may capture the impact of living in IDP camps rather than exposure to violence. In panel 5 of Table 5 we control for the share of district population living in IDP camps. The results remain qualitatively identical and also the magnitude of the impact of violence on social capital remains similar.

\section{The presence of NGOs}

Similarly, it is legitimate to question whether the increase in social capital, identified in 2012 in districts affected by the violence, results from NGO mobilization. Fearon et al. (2009), for instance, show that communities more targeted by community-driven reconstruction programs in Liberia display more trust and social cohesion. Can the recovery in social capital witnessed in northern Uganda be due to NGO activities flocking in war affected areas? We collect data on the presence of NGOs at the district level from the Uganda National NGO Directory, a database initiated by the Uganda National NGO Forum in November 2009 to serve national and international development partners. ${ }^{21}$ The figures reported in the directory capture the distribution of NGOs in recent years (2009-2013). We create two measure of district-level NGO presence: one reporting the total number of NGOs operating in each district, the second focusing only on community-based NGOs to test more directly for the effect found by Fearon et al. (2009). We restrict the test only to the specification of the model focusing on the impact of violence on social capital in 2012, since our data on NGOs refers to that period. The results of our tests, reported in the last two panels of Table 5, suggest that the recovery of social capital observed in violent districts cannot be entirely explained by NGO mobilization. Once we control for the number of NGOs, we still find that on average social capital levels in 2012 exceed the 2000 levels in regions affected by the violence. ${ }^{22}$

\footnotetext{
${ }^{21}$ http://www.ugandangodirectory.org/

${ }^{22}$ The coefficients for trust in 2012 turns non significant when we replicate these tests without Acholi districts.
} 


\subsubsection{Alternative estimation models}

Since the information on conflict intensity is available at the district level, a sensible robustness check is to run our model using the district as the unit of observation. Both dependent variables and controls are averaged at the district level. The results in the first panel of Table 6 remain unaffected, despite the drastic reduction of observations (from 4,500 to 64).

Next, since the responses to the $\mathrm{AB}$ questions on trust and membership are categorical in nature, we replicate the estimations using the original categorical nature provided by the $\mathrm{AB}$. Using an (ordered) probit model produces estimates that are qualitatively identical to our baseline OLS estimates (see panel 2 in Table 6).

We also estimate our empirical model using both OLS and probit with an alternative binary coding for our associational membership variables: non members and inactive members are coded 0 and active members and leaders are coded 1 . This test addresses the concern of "over-determined" participation, i.e. potentially forced or nudged joining of associations to access support by the government or NGOs in times of war (which may be considered inactive membership by respondents). The binary coding isolates the impact of violence on "active" membership. The results, reported in panels 3 and 4 of Table 6 , remain qualitatively identical.

Table 6 about here

\subsubsection{Alternative conflict definitions}

A distinguishing feature of the conflict in the north of Uganda was the brutality of the violence against civilians. We therefore run an alternative model in which conflict intensity is measured by attacks on civilians, so excluding battles between the army and rebel factions, allowing us to test whether the impact of violence on civilians has a differential effect on social capital. The results, reported in panel 5 of Table 6 , suggest that violence on civilians had a stronger impact on social capital as the size of the coefficients slightly increases. 
Next, we replace our measure of violence with the logged number of fatalities also reported in the ACLED database. Once more, the results obtained are similar to our baseline specification. The only difference concerns the negative coefficient regarding membership in trade union/farmer organizations in 2005, which now turns significant.

Adopting the Uppsala Conflict Data Program (UCDP) as an alternative source to measure conflict intensity produces also similar estimates. ${ }^{23}$ We report in panels 7 and 8 of Table 6 the results of the robustness checks when using the number of violent events, and the number of fatalities as reported by UCDP, respectively.

Throughout the paper we run our analysis capturing conflict intensity by the logged number of violent events. As a robustness check and to reduce potential measurement error due to uneven quality-control issues in the ACLED database (Eck 2012), we repeat our estimation adopting the logged event days, i.e. the number of days with LRA events, as an alternative measure of conflict intensity.

Finally, we repeat our main specification when measuring conflict intensity by the number of events (instead of logged events). The results - displayed in the last two panels of Table 6 - do not change qualitatively except in the last panel for the impact of violence on the membership in trade union/farmer organizations in 2005, which turns significant.

\subsubsection{Alternative empirical strategy}

Given the similarities between this work and Rohner et al. (2013), a relevant robustness check consists in replicating our analysis adopting their empirical strategy. In Table 7, we produce all specifications of Table 1 in Rohner et al. (2013), with and without ethnic controls and adopting violent events and fatalities as alternative measures of conflict. In panel 1 we regress 2012 individual-level generalized trust on the violence taking place in the county of the respondent in the period 2000-2008, controlling for the 2000 district average trust. In panel 2 we repeat the

\footnotetext{
${ }^{23}$ http://www.pcr.uu.se/research/ucdp/datasets/
} 
exercise using as dependent variable 2008 levels of generalized trust. We restrict the analysis to the counties that have been surveyed both in 2008 and 2012 to make the comparison meaningful. We find a negative and sizable impact of conflict on 2008 generalized trust, but no impact on 2012 generalized trust. ${ }^{24}$ This recovery by 2012 is in line with the message of our paper.

Table 7 about here

\subsubsection{IV estimates}

Our findings may result from reversed causality: violence may be the consequence rather than the cause of changes in social capital, because, for instance, rebel recruitment may be easier in regions where social capital is decreasing. Blattman (2009) argues that this is unlikely in the northern Ugandan context, as a large share of the Lord's Resistance Army was composed of abducted youths. Furthermore, our findings may suffer from attenuation bias because conflict events may be measured with error. For instance, events in very insecure areas may have received little news coverage, leading to an underestimation of violence in the most affected areas (Verpoorten 2012). An IV strategy partly corrects for this.

We instrument for the interaction term of interest using the distance to Sudan interacted with the year dummy. The instrument is relevant because, as part of the Sudanese support for the LRA rebels, the LRA was provided with logistics and bases on Sudanese territory from where they organized raids. Rohner et al. (2013) adopt the same instrument and argue that it satisfies the exclusion restriction by showing that distance to Sudan has no significant relationship with generalized trust in counties without violence. In Table A.3 of the appendix we replicate this falsification exercise and show that for six out of our seven dependent variables there is no statistically significant reduced form relationship (between our social capital measures and distance to Sudan) in districts without LRA violence. For the estimation of membership in community

\footnotetext{
${ }^{24}$ The small differences between our results in panel 2 and Rohner et al. (2013) Table 1 are entirely due to the slightly different sample of counties included in the analysis.
} 
development associations in 2012 the falsification test does not support the suitability of our instrument.

Table 8 about here

The first stage results, reported in Table A.2 of the appendix, indicate that the instruments are relevant, with the estimated coefficient on the instrument significantly different from zero. The second stage results, reported in Table 8 , largely confirm our OLS results. In Table 8 we also report the Durbin-Wu-Hausman tests. The null hypothesis of the consistency of the OLS estimates cannot be rejected at the five percent level for columns (1), (2), (5), (6), but it is rejected for columns (3), (4) and (7). So, for these latter columns, IV results are more reliable. We therefore report the IV estimates of all robustness checks in the appendix (Tables A.4 and A.5). The difference between results obtained in the two approaches remains very small.

\section{Discussion of the channels}

In section 3.2 we presented three channels linking war or trauma to inter-personal relations. In light of our results, we can make informed guesses about which channels operated in the context of the Ugandan conflict.

First, our results challenge the view according to which traumatic experiences foster pro-social behavior, at least in the short run. Moreover, based on the quick recovery of social capital identified, we can also exclude that exposure to violence resulted in real psychological change modifying the perception of other individuals, as such change would leave traces a few years after the end of the conflict. Bauer et al. (2014) found that experiencing war in Sierra Leone and in the Republic of Georgia had a long-lasting impact on pro-social motivations only for individuals aged 7-20 at the time of violences. The likelihood for traumatic experiences to change social behavior may be particularly high during this stage of personal development. We test for the heterogeneity of the 
impact across age by restricting our model to the sample of individuals aged 7-20 during LRA violence. The results in Table 9, however, do not reveal different results among this category, further reducing the empirical support for the psychological change channel.

Table 9 about here

The two alternative mechanisms proposed, the rule-of-thumb and the interaction frequency, seem more in line with our results. Both mechanisms would predict a negative impact on social capital amidst violence, and both are compatible with a temporary impact. Regarding the first mechanism, since LRA was mainly composed by Acholi individuals, a sensible rule-of-thumb might have been "not to trust Acholi people" as long as the violence was taking place. When violence stops, however, they may revert back to their pre-violence social behavior.

Second, since trust is partly the result of social interactions, the breakdown of associational membership may have reduced generalized trust in the northern districts. This channel is also consistent with a temporary effect: once social networks are restored in the aftermath of the emergency, trust levels can recover as well. Unlike for the previous mechanism, however, if the reason for lower trust is merely based on scarce interaction, the drop in trust should not be restricted to a specific category (e.g. individual belonging to the Acholi ethnic group) but involve all individuals with which interaction has reduced.

Following these lines of thought, we use information on trust in own ethnic group recorded by the AB surveys to test the plausibility of the different mechanisms. Only the 2000 and 2005 $\mathrm{AB}$ questionnaires include questions on in-group trust. If people living in areas affected by LRA violence adopted a rule of mistrust only vis-a-vis Acholi individuals, we should find that 2005 trust in co-ethnics is not negatively affected by LRA violence outside Acholi districts. For the test to be meaningful, we need to exclude Acholi districts as in that context coethnics and violence perpetrators blend in the same category. The results, reported in Table 10, indicate that the level of trust in coethnics increased in 2005 in non-Acholi districts affected by LRA operations. This 
finding suggests that the drop in generalized trust, documented in this study, stems from increased caution towards certain categories of individuals associated with the perpetrators of violence, which is consistent with a (temporary) rule of thumb.

Table 10 about here

Above and beyond the mechanisms through which violence affects social capital, an important finding of our study concerns the duration of the impact. In 2012, about five years after the end of the violence, the level of generalized trust fully recovered to its pre-violence levels. In other words, even though our results are more in line with the pessimistic findings of Cassar et al. (2011) and Rohner et al. (2013), toning down the enthusiasm sparked by the initial micro-founded studies on the effect of violence on social capital (Bellows and Miguel 2009, Blattman 2009), we believe that our results should allow for moderate optimism. While the social fabric is affected, its disruption is not long-lasting and therefore is not standing in the way of a normalization of the social and economic interactions.

\section{Conclusions}

We analyzed the impact of armed conflict in Uganda, making use of three nationwide surveys that bracket the peak in LRA violence taking place in the north of the country. Our findings indicate that social capital decreased amidst violence. However, we also document that social capital strongly increased in the post-conflict phase, fully recovering to pre-violence levels.

More specifically, we find that both the level of trust and participation in religious and community associations decreases when transiting from relative peace to violence. Regarding participation in economic associations (farm, trade, business and professional voluntary organizations), no robust negative impact was detected. On a more positive note, our results suggest a strong post-violence recovery process. In 2012, only a few years after the end of violence, the level of trust strongly 
increases in the affected areas.

How do these findings fit in the literature? At this stage, the evidence from existing studies balances between a positive and a negative civil war impact on social capital. So does our study, which suggests that much may depend on the time span between the measurement of social capital and the end of violence. In addition, the overall community-level effect may depend heavily on what proportion of the community was directly exposed to violence as a witness, perpetrator or victim, and what part of the community was only indirectly affected, e.g. by displacement and fear. 


\section{References}

ACCORD (2010): Initiatives to end the violence in northern Uganda. Conciliation Resources.

Adhvaryu, A., and J. Fenske (2013): "War, Resilience and Political Engagement in Africa," Working Paper Series 2013-08, CSAE.

Akresh, R., and D. De Walque (2008): "Armed Conflict and Schooling: Evidence from the 1994 Rwandan Genocide," HiCN Working Papers 47, Households in Conflict Network.

Allen, T. (2006): Trial justice: the international criminal court and the Lord's Resistance Army. Zed Books.

Bauer, M., A. Cassar, J. Chytilova, and J. Henrich (2014): "War's Enduring Effects on the Development of Egalitarian Motivations and In-Group Biases," Psychological Science, 252(1), $47-57$.

Becchetti, L., P. Conzo, And A. Romeo (2014): "Violence, trust, and trustworthiness: evidence from a Nairobi slum," Oxford Economic Papers, 66(1), 283-305.

Bellows, J., And E. Miguel (2006): "War and Institutions: New Evidence from Sierra Leone," American Economic Review Papers and Proceedings, 96 (2), 394-399.

(2009): "War and local collective action in Sierra Leone," Journal of Public Economics, $93,1144-1157$.

Beugelsdijk, S., H. L. De Groot, and A. B. van Schaik (2004): "Trust and economic growth: a robustness analysis," Oxford Economic Papers, 56(1), 118-134.

Blattman, C. (2009): "From Violence to Voting: War and Political Participation in Uganda," American Political Science Review, 103(2), 231-247. 
Boyd, R., And P. J. Richerson (2005): The Origin and Evolution of Cultures. Oxford University Press, Oxford.

Bozzoli, C., T. Brück, and T. Muhumuza (2010): "Conflict Experiences and Household Expectations on Recovery: Survey Evidence from Northern Uganda," HiCN Working Papers 88, Households in Conflict Network.

Cameron, A. C., and D. L. Miller (forthcoming): "A Practitioner's Guide to Cluster-Robust Inference," Journal of Human Resources.

Cassar, A., P. Grosjean, and S. Whitt (2011): "Civil War, Social Capital and Market Development: Experimental and Survey Evidence on the Negative Consequences of Violence," SSRN Working Paper 1917111.

Coleman, J. S. (2000): "Social capital in the Creation of Human Capital," American Journal of Sociology, 94, 95-120.

Colletta, N. J., And M. L. Cullen (2000): Violent conflict and the transformation of social capital. The World Bank, Washington, D.C.

Collier, P., V. L. Elliot, H. Hegre, A. Hoeffler, M. Reynal-Querol, and N. Sambanis (2003): Breaking the Conflict Trap: Civil War and Development Policy. World Bank and Oxford University Press.

Collins, R. L., S. E. Taylor, and L. A. Skokan (1990): "A better world or a shattered vision? Changes in life perspectives following victimization," Social Cognition, 8, 263-285.

De Jong, T. V. M. (2002): Trauma, War, and Violence: Public Mental Health in Socio-Cultural Context. Kluwer Academic Publishers, New York.

De Luca, G., and M. Verpoorten (forthcoming): "Civil War and Political Participation: Evidence from Uganda," Economic Development and Cultural Change. 
Dolan, C. (2009): Social Torture: The Case of Northern Uganda, 1986-2006. Berghahn Books.

Doom, R., and K. Vlassenroot (1999): “Kony's Message: a New Koine? The Lord's Resistance Army in Northern Uganda," African Affairs, 98(390), 5-36.

ECK, K. (2012): "In data we trust? A comparison of UCDP GED and ACLED conflict events datasets," Cooperation and Conflict, 47(1), 124-141.

Fearon, J. D., M. Humphreys, and J. M. Weinstein (2009): "Can Development Aid Contribute to Social Cohesion after Civil War? Evidence from a Field Experiment in Post-conflict Liberia," American Economic Review, 99(2), 287-91.

Gilligan, M. J., B. J. Pasquale, and C. Samil (2014): "Civil War and Social Cohesion: Lab-in-the-Field Evidence from Nepal," American Journal of Political Science, 58(3), 604-619.

Glaeser, E. L., D. I. Laibson, J. A. Scheinkman, and C. L. Soutter (2000): "Measuring Trust," The Quarterly Journal of Economics, 115(3), 811-846.

Guiso, L., P. Sapienza, and L. Zingales (2004): "The Role of Social Capital in Financial Development," The American Economic Review, 94(3), 526-556.

Knack, S., And P. Keefer (1995): "Institutions and Economic Performance: Cross-Country Tests Using Alternative Measures," Economics and Politics, 7, 207-227.

(1997): "Does social capital have an economic payoff? A cross-country investigation," Quarterly Journal of Economics, 112, 1251-1288.

Lehrer, K. (2010): "Gender Differences in Labor Market Participation: Evidence from Displaced People's Camps in Northern Uganda," Working paper.

Lewis, M. P. (2009): Ethnologue: Languages of the World. Sixteenth edition. SIL International, Dallas, TX. 
Miguel, E., And G. Roland (2011): "The long-run impact of bombing Vietnam," Journal of Development Economics, 96(1), 1-15.

Minnesota Population Center (2010): Integrated Public Use Microdata Series, International: Version 6.0 [Machine-readable database] Minneapolis: University of Minnesota.

Nunn, N., And L. Wantchekon (2011): "The Slave Trade and the Origins of Mistrust in Africa," American Economic Review, 101(7), 3221-52.

Putnam, R., R. Leonardi, and R. Y. Nanetti (1993): Making Democracy Work. Princeton University Press, Princeton, NJ.

Putnam, R. D. (2000): Bowling alone: The collapse and revival of American community. Simon and Schuster.

Raleigh, C., A. Linke, H. Hegre, and J. Karlsen (2010): "Introducing ACleD: An Armed Conflict Location and Event Dataset," Journal of Peace Research, 47(5), 651-660.

Restrepo, J. A., M. Spagat, and J. F. Vargas (2006): "Special Data Feature; The Severity of the Colombian Conflict: Cross-Country Datasets Versus New Micro-Data," Journal of Peace Research, 43(1), 99-115.

Rohner, D., M. Thoenig, and F. Zilibotti (2013): "Seeds of distrust: conflict in Uganda," Journal of Economic Growth, 18(3), 217-252.

SERneels, P., And M. Verpoorten (forthcoming): "The impact of armed conflict on economic performance: Evidence from Rwanda," Journal of Conflict Resolution.

Sobel, J. (2002): "Can We Trust Social Capital?," Journal of Economic Literature, 40(1), 139154.

Verpoorten, M. (2012): "Detecting hidden violence: The spatial distribution of excess mortality in Rwanda," Political Geography, 31(1), 44-56. 
Voors, M. J., E. E. M. Nillesen, P. Verwimp, E. H. Bulte, R. Lensink, and D. P. VAN Soest (2012): "Violent Conflict and Behavior: A Field Experiment in Burundi," American Economic Review, 102(2), 941-64.

Weil, D. (2009): Economic Growth. Pearson International Edition.

Weinstein, N. D. (1989): "Effects of Personal-Experience on Self-Protective Behavior," Psychological Bulletin, 105, 31-50.

WoOlcock, M., And D. NARAYAn (2000): "Social Capital: Implications for Development Theory, Research, and Policy," The World Bank Research Observer, 15(2), 225-249.

ZaK, P. J., And S. KnACK (2001): "Trust and Growth," The Economic Journal, 111(470), 295321. 


\section{Figures}

Figure 1: LRA violence in Uganda

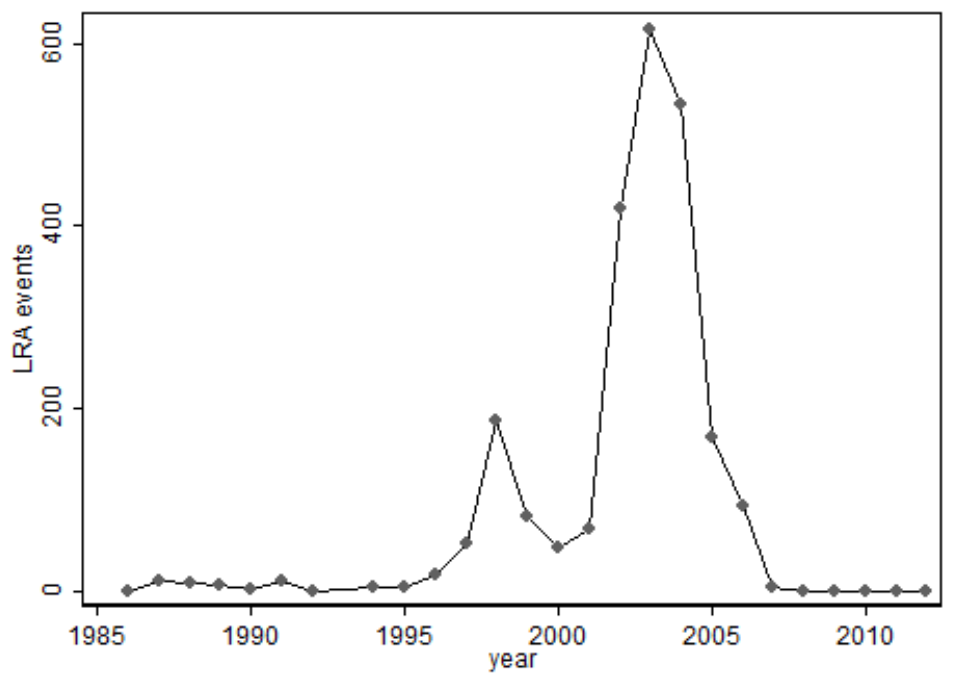




\section{Tables}

Table 1: Afrobarometer samples

\begin{tabular}{lccc}
\hline & Number of individuals \\
& 2000 & 2005 & 2012 \\
\hline Central & 751 & 656 & 632 \\
East & 559 & 584 & 640 \\
North & 369 & 544 & 544 \\
West & 595 & 616 & 584 \\
\hline Total & 2271 & 2400 & 2400 \\
\hline Note: Samples nationally & represen- \\
tative for each survey
\end{tabular}




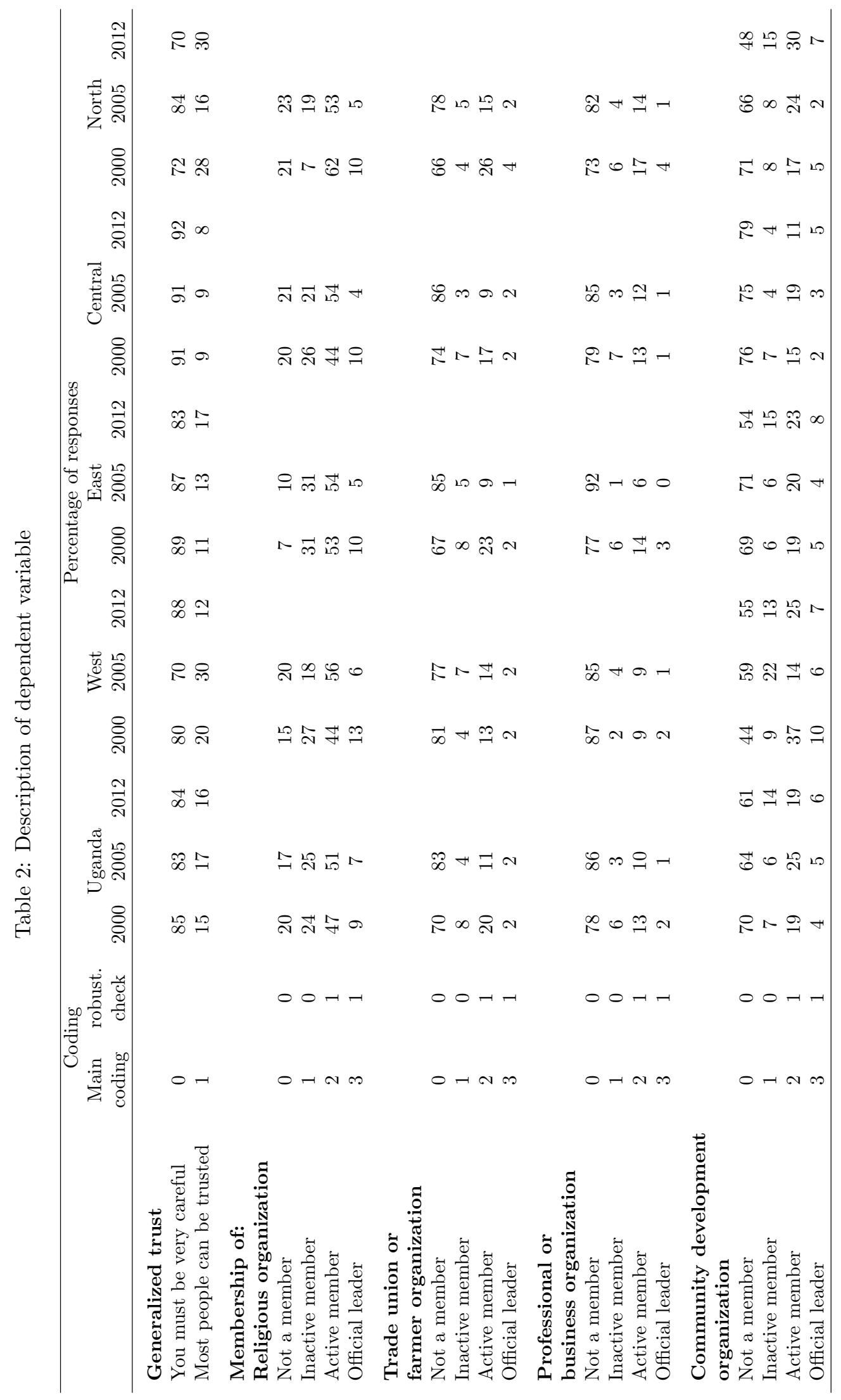


Table 3: Descriptive statistics

\begin{tabular}{lccc}
\hline & 2000 & 2005 & 2012 \\
\hline Dependent variables & & & \\
Generalized trust & 0.15 & 0.17 & 0.16 \\
Religious organization & 1.46 & 1.48 & \\
Trade union or farmer organization & 0.53 & 0.32 & \\
Professional or business organization & 0.39 & 0.26 & \\
Community development organization & 0.56 & 0.70 & 0.71 \\
& & & \\
Explanatory variables & & & \\
LRA events 2000-2005 & 33.67 & 39.69 & \\
Other events 2000-2005 & 8.93 & 10.08 & \\
LRA events 2000-2012 & 37.61 & & 46.72 \\
Other events 2000-2012 & 20.38 & & 23.06 \\
LRA attacks 2000-2005 & 14.74 & 18.16 & \\
Other attacks 2000-2005 & 4.37 & 5.28 & \\
LRA attacks 2000-2012 & 15.85 & & 18.07 \\
Other attacks 2000-2012 & 12.06 & & 13.93 \\
Ethno-Linguistic fractionalization & 0.43 & 0.42 & 0.41 \\
Age & 33.40 & 32.55 & 35.18 \\
Age squared & 1275 & 1207 & 1402 \\
Male & 0.50 & 0.50 & 0.50 \\
Urban & 0.14 & 0.30 & 0.14 \\
Education level & 3.20 & 3.39 & 3.30 \\
Ethnicity (\%): & & & \\
Ateso & 4.76 & 7.25 & 7.25 \\
Luganda & 25.36 & 18.63 & 20.5 \\
Lugbara & 2.91 & 4.92 & 3.92 \\
Lumasaba & 5.15 & 4.00 & 4.17 \\
Luo (includes Acholi) & 12.86 & 12.92 & 11.33 \\
Lusoga & 9.91 & 9.88 & 10.08 \\
Rukiga & 6.43 & 6.25 & 5.63 \\
Runyankole & 2.95 & 11.04 & 12.71 \\
Runyoro & 3.43 & 3.04 & 2.67 \\
Rutooro & 11.93 & 3.63 & 2.04 \\
Others & 13.17 & 15.42 & 17.96 \\
\hline
\end{tabular}

Notes: Attacks record attacks on civilians only, whereas events include attacks on civilians and battle events. Education level is a categorical variable taking values between 0 and 6 , with 0 denoting no schooling and 6 post-university education; the Acholi ethnic group is a subgroup of the broader category of Luo. 


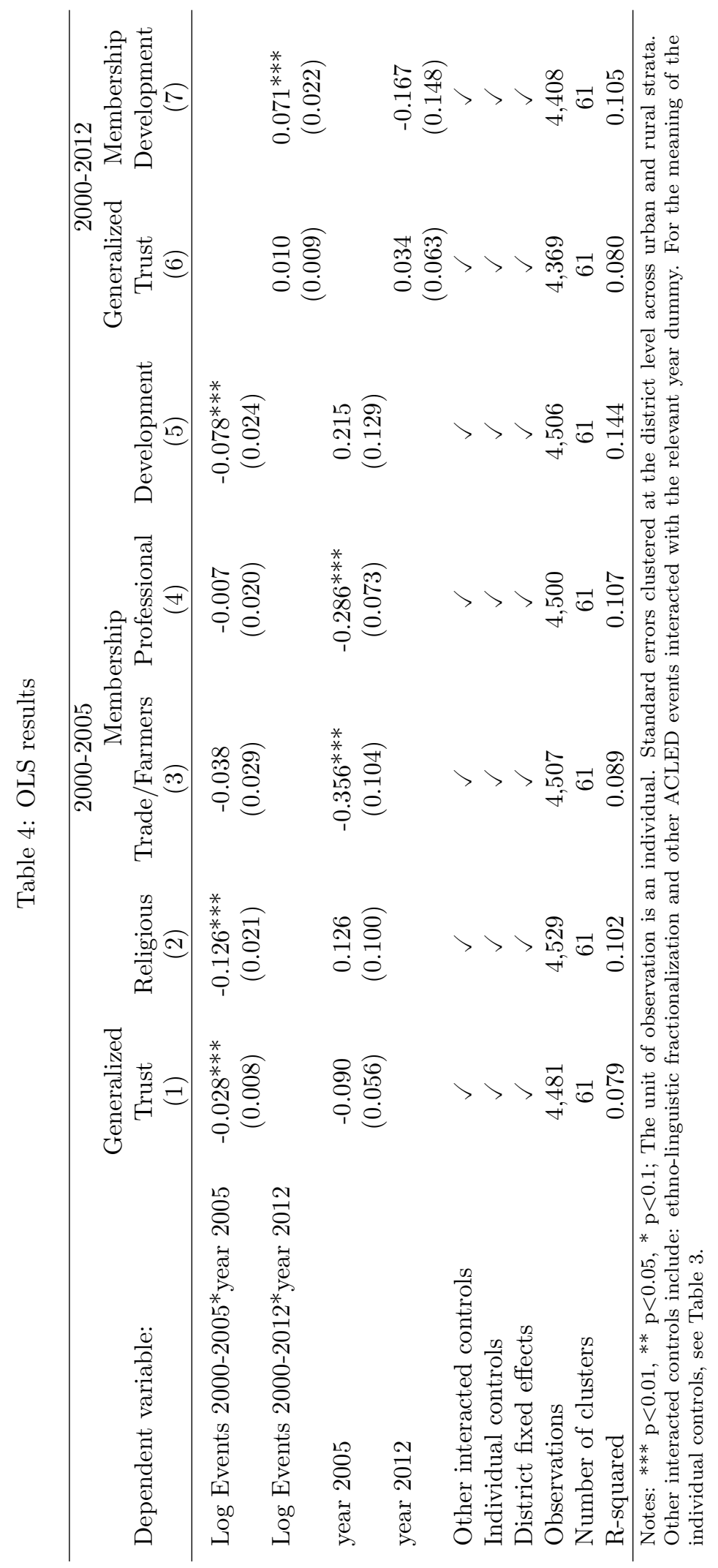




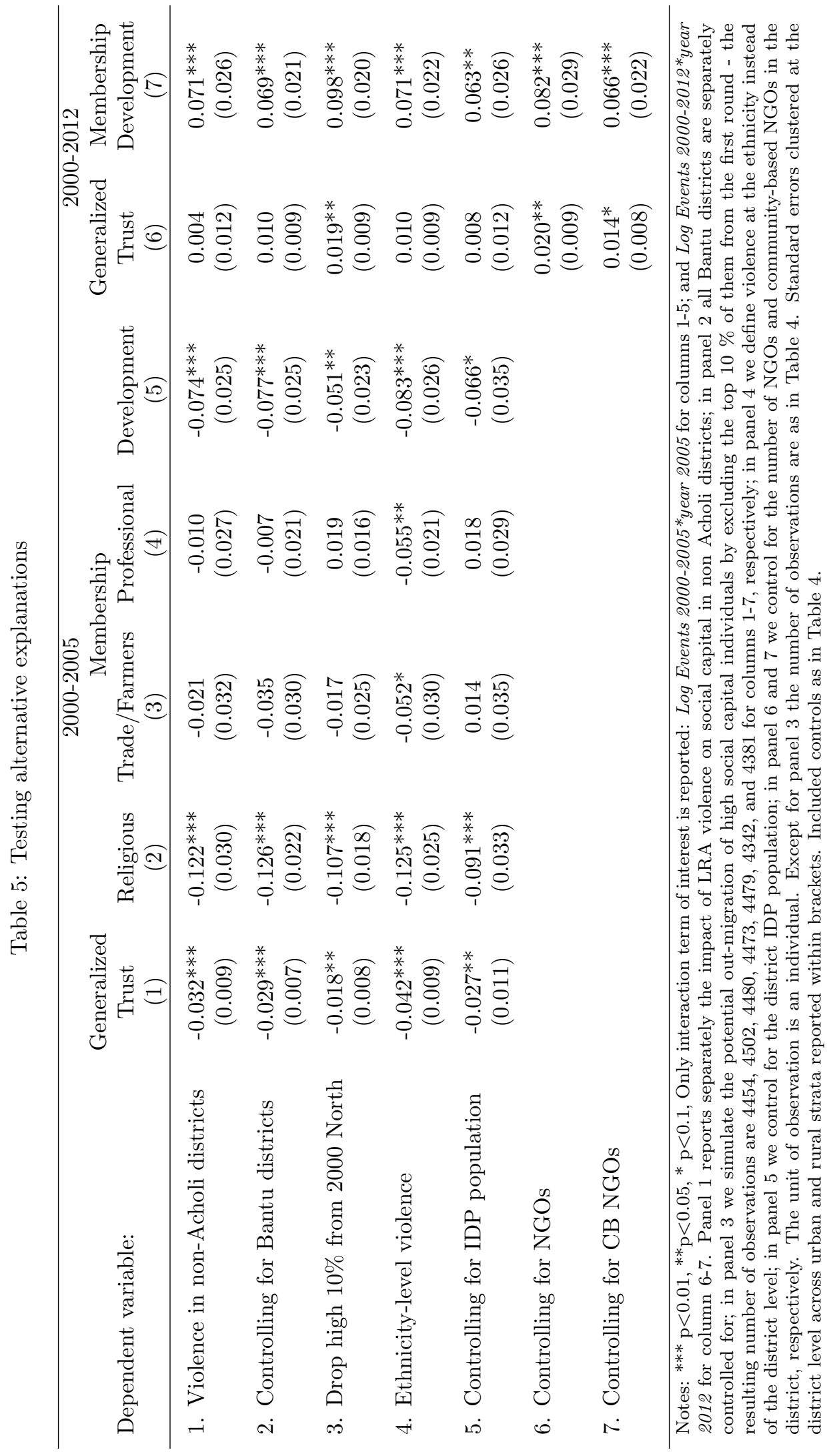




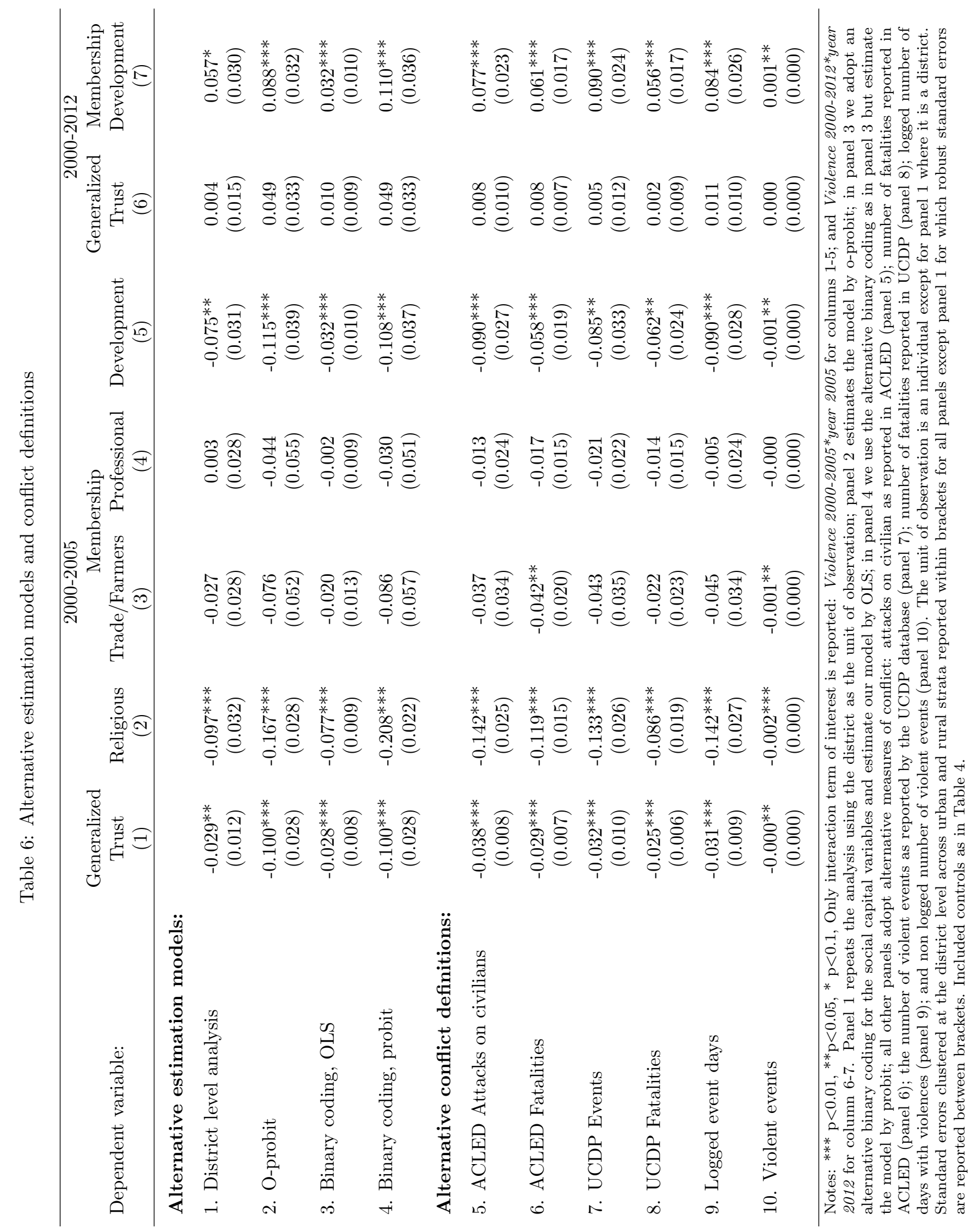




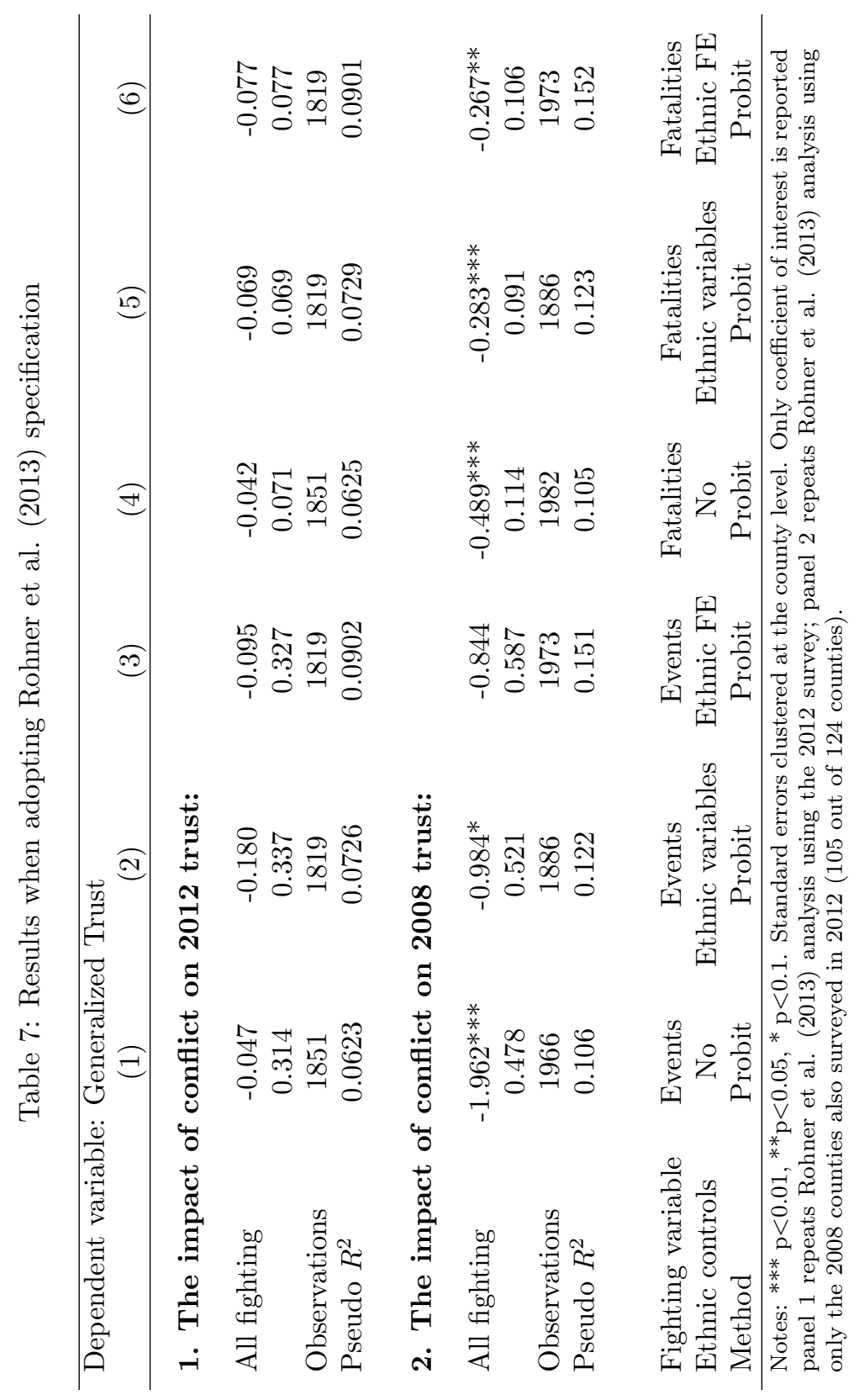




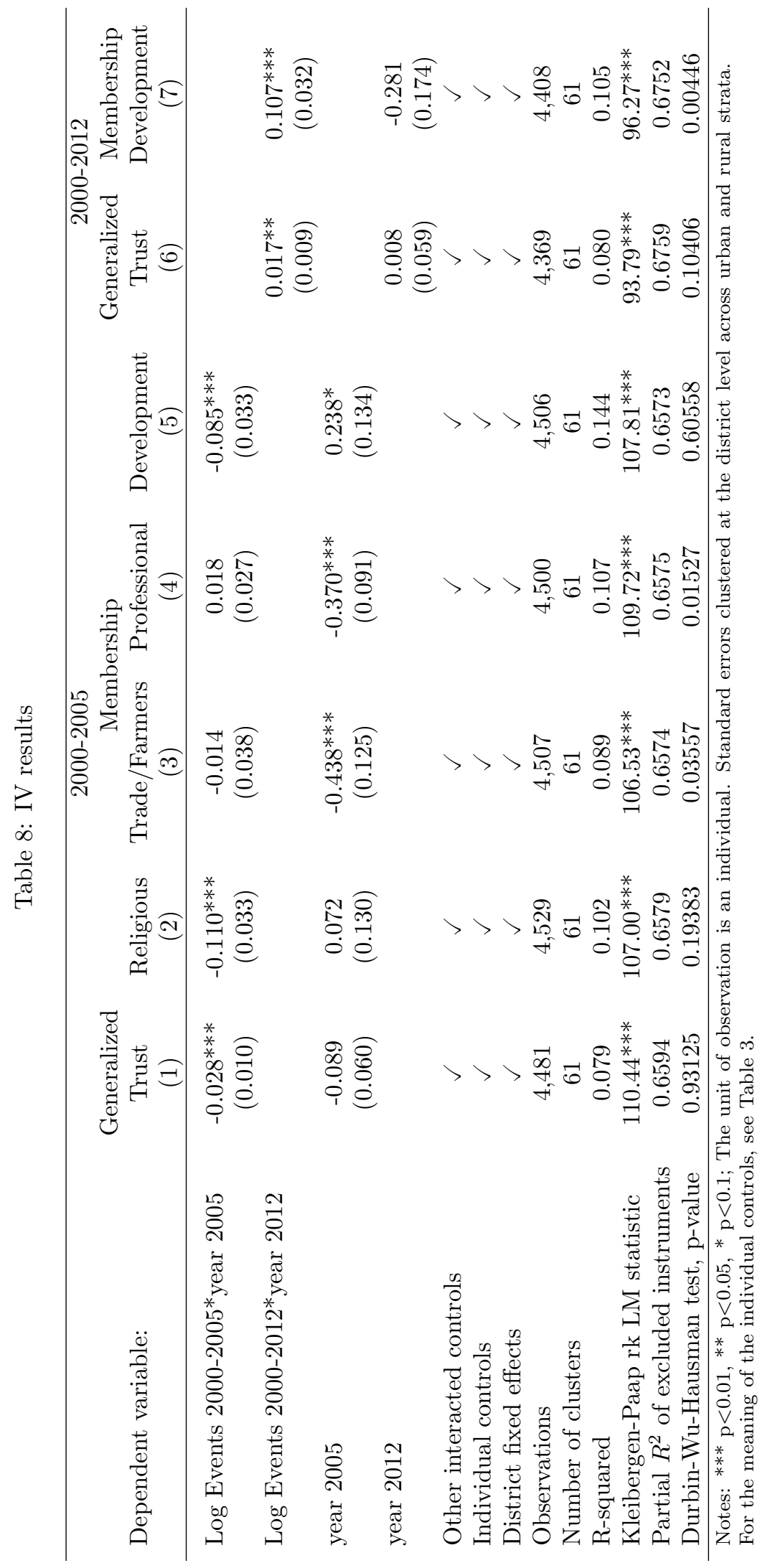




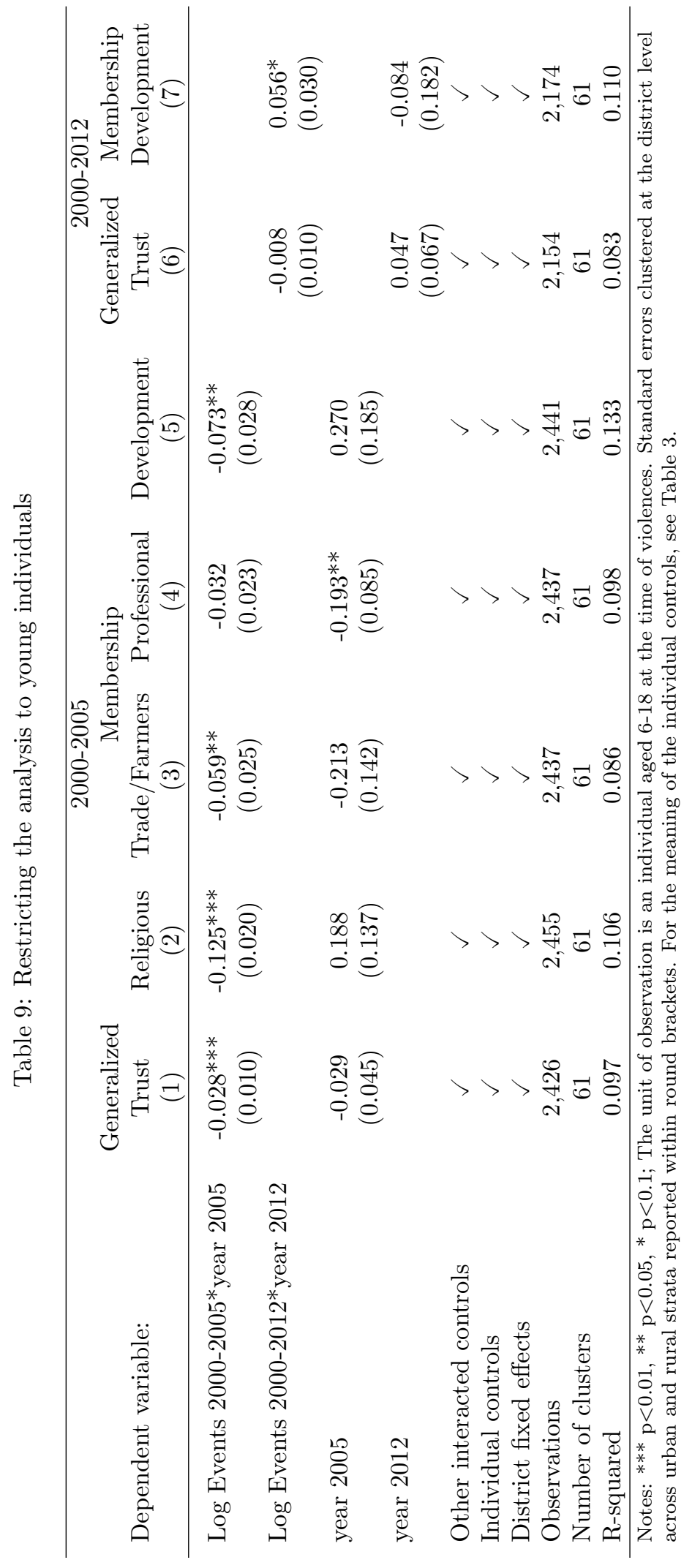


Table 10: Violence on trust towards coethnics

\begin{tabular}{lcc}
\hline \multirow{2}{*}{ Dependent variable: } & \multicolumn{2}{c}{$2000-2005$} \\
& Trust coethnics \\
& $(1)$ & $(2)$ \\
\hline Log Events 2000-2005*year 2005 & $0.026^{*}$ & $0.056^{*}$ \\
& $(0.015)$ & $(0.031)$ \\
year 2005 & $-0.252^{* * *}$ & $-0.442^{* *}$ \\
& $(0.073)$ & $(0.179)$ \\
Other interacted controls & $\checkmark$ & \\
Individual controls & $\checkmark$ & $\checkmark$ \\
District fixed effects & $\checkmark$ & $\checkmark$ \\
Observations & 4,342 & 4,342 \\
Number of clusters & 61 & 61 \\
R-squared & 0.132 & 0.137 \\
\hline
\end{tabular}

Notes: ${ }^{* * *} \mathrm{p}<0.01,{ }^{* *} \mathrm{p}<0.05,{ }^{*} \mathrm{p}<0.1$; The unit of observation is an individual. Standard errors clustered at the district level across urban and rural strata reported within brackets. Codings for the dependent variable: binary variable (column 1) and a variable ranging from 0 to 3 , with 3 representing high trust in coethnics (column 2). For the meaning of the individual controls, see Table 3. 


\section{Appendix}

Table A1: OLS using 2005-12

\begin{tabular}{lcc}
\hline Dependent variable: & $\begin{array}{c}\text { Generalized } \\
\text { trust } \\
(1)\end{array}$ & $\begin{array}{c}\text { Membership } \\
\text { development } \\
(2)\end{array}$ \\
\hline Log Events 2005-12*year 2012 & $0.080^{* * *}$ & $0.283^{* * *}$ \\
& $(0.022)$ & $(0.060)$ \\
Other interacted controls & $\checkmark$ & $\checkmark$ \\
Individual controls & $\checkmark$ & $\checkmark$ \\
District fixed effects & $\checkmark$ & $\checkmark$ \\
Year fixed effects & $\checkmark$ & $\checkmark$ \\
Observations & 4,594 & 4,600 \\
Clusters & 61 & 61 \\
R-squared & 0.060 & 0.121 \\
\hline
\end{tabular}

Notes: *** $\mathrm{p}<0.01, * * \mathrm{p}<0.05, * \mathrm{p}<0.1$; Standard errors clustered at the district level across urban and rural strata reported within brackets. 


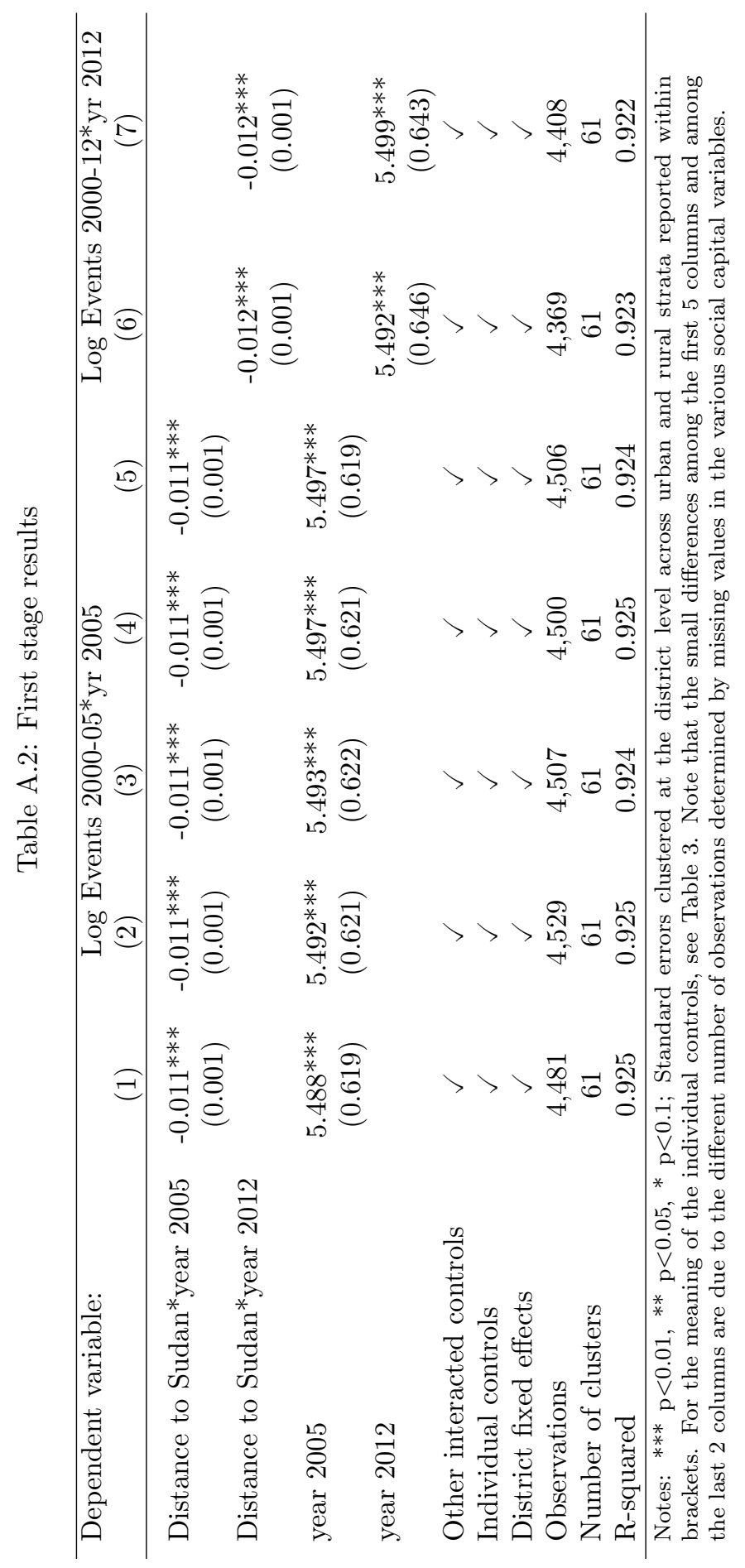




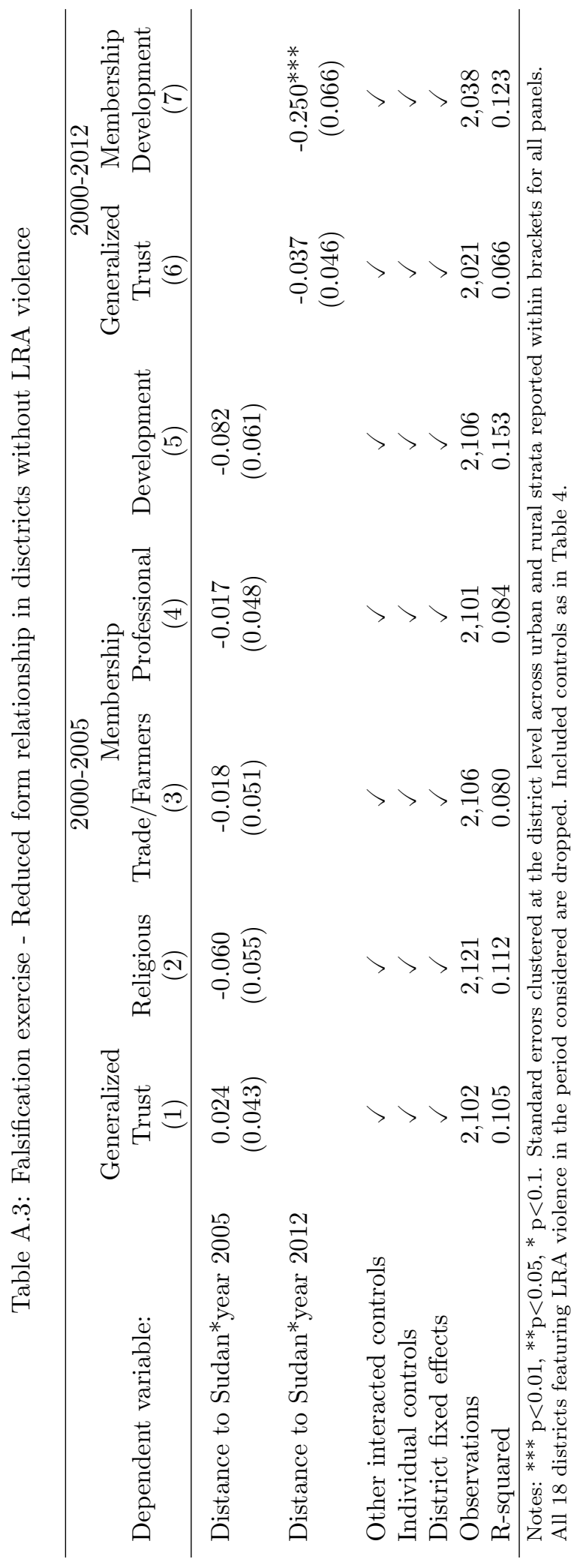




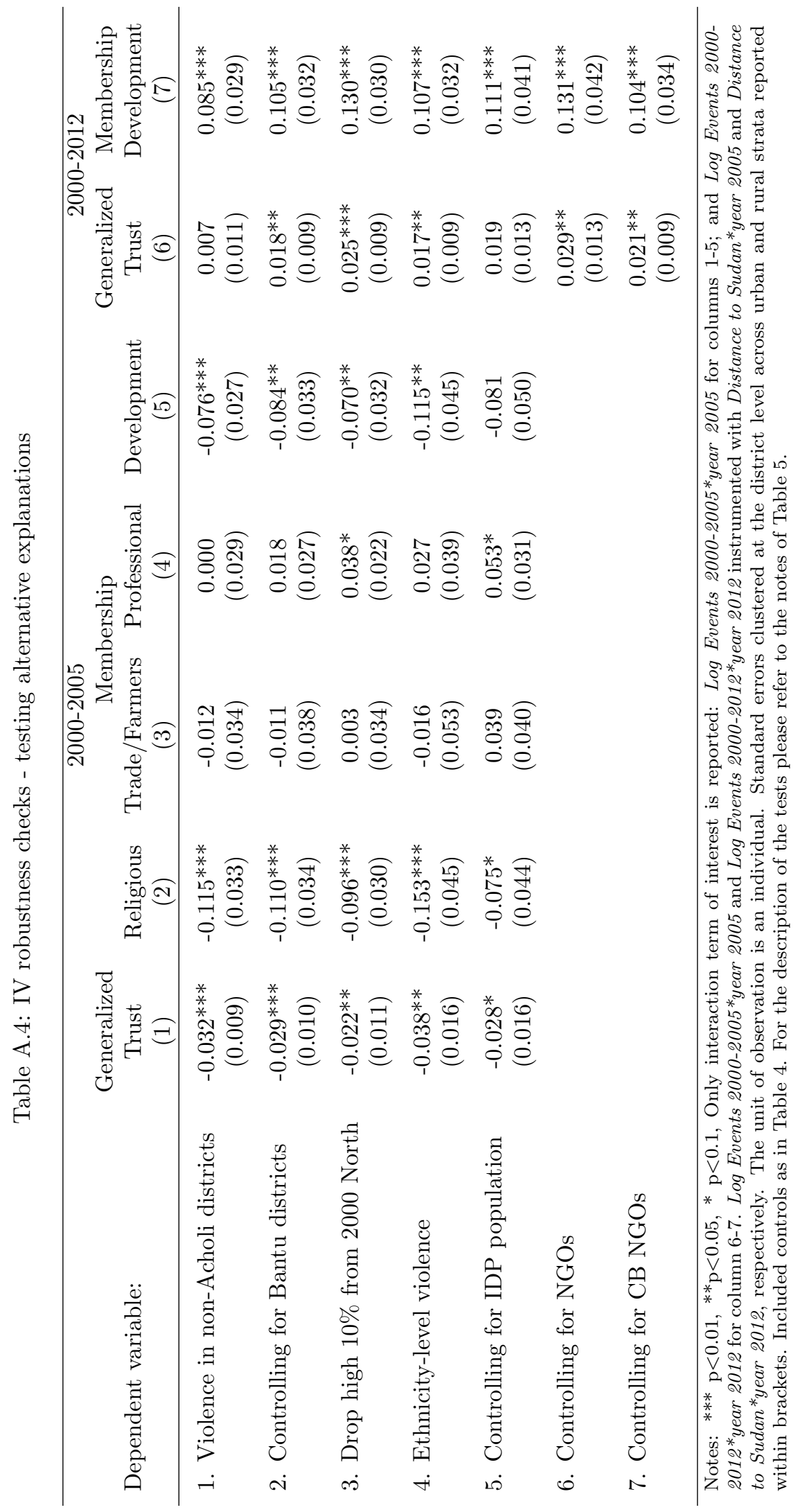




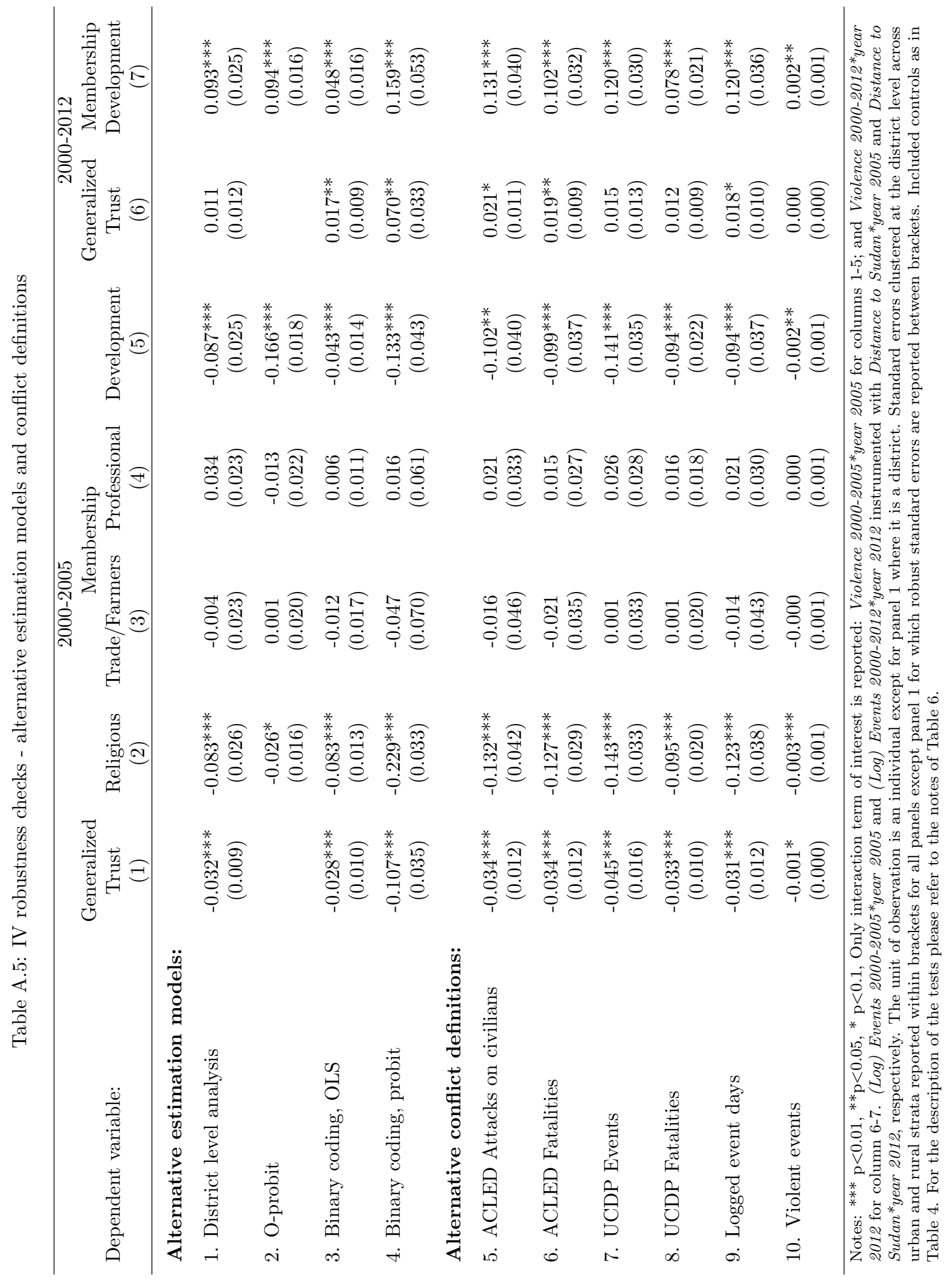

